\title{
RANCANGAN USAHA AGRIBISNIS TANAMAN SAYURAN BERBASIS HIDROPONIK
}

\section{BUSINESS PLAN AGRIBUSINESS VEGETABLES BASED HYDROPONICS}

\author{
Asriani $^{* 1}$, Nurcayah ${ }^{1}$, Dhian Herdhiansyah ${ }^{2}$ \\ ${ }^{1}$ Universitas Muhammadiyah Kendari, Jl. KH.Ahmad Dahlan. No. 10 Kendari \\ ${ }^{2}$ Universitas Halu Oleo, J1. H.A.E Mokodompit, Anduonohu Kendari \\ *E-mail: asriani@umkendari.ac.id \\ (Diterima 26-12-2021; Disetujui 22-01-2022)
}

\begin{abstract}
ABSTRAK
Program pemerintan tentang katahanan pangan perlu untuk mendapat dukungan melalui penerapan teknologi tepat guna bidang pertanian. Hidroponik merupakan teknologi budidaya tanaman sayuran pertanian yang perlu untuk dikembangkan dalam upaya meningkatkan produksi sayuran dan mendorong pengembangan wirausaha agribisnis. Adapun tujuan dari penelitian ini adalah pengembangan teknologi bidudaya tanaman hidroponik melali sistem Nutrient Film Technique (NFT) dan sistem Wick. Metode yang digunakan adalah metode kualitatif berupa penerapan secara aplikatif tentang cara budidaya hidroponik. Hasil penelitian berupa rancangan isntalasi dan teknik budidaya hidroponik yang dapat dikembangkan menjadi bahan ajar dan wirausaha baru dibidang pertanian.
\end{abstract}

Kata kunci: Budidaya, sayuran, hidroponik, wirausaha

ABSTRACT

The government's program on food security needs to get support through the application of appropriate technology in the agricultural sector. Hydroponics is an agricultural vegetable cultivation technology that needs to be developed in an effort to increase vegetable production and encourage the development of agribusiness entrepreneurship. The purpose of this research is the development of hydroponic plant cultivation technology through the Nutrient Film Technique (NFT) system and the Wick system. The method used is a qualitative method in the form of an applicative application of hydroponic cultivation. The results of the research are in the form of installation designs and hydroponic cultivation techniques that can be developed into teaching materials and new entrepreneurs in the field of agriculture.

Keywords: Cultivation, vegetables, hydroponics, entrepreneurship

\section{PENDAHULUAN}

Hidroponik berasal dari bahasa Latin hydros yang berarti air dan phonos yang berarti kerja. Arti harfiah dari hidropnik adalah kerja air (Masduki 2018). Bertanam secara hidroponik kemudian di kenal dengan medium bertanam tapa tanah (soilless cultivation, soilless culture). Mulanya orang-orang bertanam dengan metode hidroponik dengan wadah yang berisi air dimana air tsb sudah dicampur dengan pupuk mikro maupun makro.

Lahan pertanian yang semakin sempit mengakibatkan peralihan fungsi laan pertanian menjadi lahan 
perindustrian. Teknologi hidroponik pada tanaman sayuran dapat dilihat sebagai salah satu solusi menghadapi tantangan lahan pertanian yang semakin sempit dan tuntutan kualitas sayuran yang semakin meningkat. Menurut (Roidah 2014) Hidroponik merupakan metode bercocok tanam dengan menggunakan media tanam selain tanah, seperti batu apung, kerikil, pasir, sabut kelapa, potongan kayu atau busa.

Teknologi tepat guna Hidroponik merupakan budidaya menanam denganmemanfaatkan media air tanpa menggunakan tanah dengan menekankan pada pemenuhan kebutuhan nutrisi bagi tanaman (Asriani, Herdhiansyah 2020)

Hidroponik menjadi solusi bagi masyarakat perkotaan yang tidak memiliki lahan yang cukup luas dan tanah yang subur untuk bercocok tanam. Melalui hidroponik, keterbatasan tersebut dapat diatasi cukup dengan menyediakan instalasi, air, nutrisi, dan bibit tanaman.

Hidroponik merupakan metode bercocok tanam yang biasanya digunakan untuk menanam sayuran sebagai upaya untuk memenuhi sumber vitamin dan mineral masyarakat sekaligus dapat memanfaatkan pekarangan yang sempit. Adapun tanaman yang sering ditanam dengan menggunakan sistem hidroponik adalah tanaman sayuran berupa sawi, bayam, selada dan kangkung (Asriani et al. 2020)

\section{METODE PENELITIAN}

Penelitian ini dilakukan di Laboratorium lapangan Fakultas Pertanian, Universitas Muhammadiyah Kendari, Sulawesi Tenggara. Pelaksanaan penelitian ini berlangsung selama 1 tahun. Metode penelitian merupakan pendekatan kualitatif dengan tujuan untuk menguraikan cara memulai usaha budidaya berbasis hidroponik dalam upaya menciptakan wirausaha.

Adapun peralatan yang digunakan yang digunakan pada penelitian ini yaitu instalasi hidroponik DFT, Instalasi Wick system, netpot serta pompa air dan penampungan. Ukuran dari instalasi DFT yang digunakan adalah rangka dengan tinggi $180 \mathrm{~cm}$ dan lebar $220 \mathrm{~cm}$ untuk lebih jelasnya terdapat pada gambar 1 . Netpot yang berfungsi sebagai penyangga bibit akan disimpan pada talang dengan ukuran diameter $5 \mathrm{~cm}$ dan jarak antar talang disesuaikan dengan perlakuan yaitu sejauh $10 \mathrm{~cm}$. Sirkulasi air yang ada pada instalasi tersebut dioperasikan dengan menggunakan pompa dan melalui pipa. Alat yang digunakan untuk pengambilan data adalah penggaris, 
timbangan analitik, kalkulator, kamera, dan alat tulis, sedangkan bahan yang digunakan adalah benih pakcoy, benih selada, rockwool dan nutrisi $\mathrm{AB}$ Mix dengan perbandingan $5 \mathrm{ml}$ nutrisi A ditambahkan dengan $5 \mathrm{ml}$ nutrisi $\mathrm{B}$ atau $(\mathrm{A}+\mathrm{B}=5+5=10 \mathrm{ml})$ untuk 1 liter air.

\section{HASIL DAN PEMBAHASAN}

\section{Budidaya Hidroponik Sistem NFT (Nutrient Film Technique)}

Teknik budidaya hidroponik dengan merupakan salah satu tipe hidroponik yang spesial karena pada metode budidaya tanaman dimana akar tanaman tumbuh pada lapisan yang dangkal dan tersirkulasi sehingga tanaman bisa memperoleh air, nutrisi dan oksigen yang cukup.

Adapun Tujuan dari penanaman hidroponik NFT untuk menghemat pemakaian lahan, pemakaian air yang sistem Nutrient Film Technique (NFT) lebih efisien untuk sirkulasinya, tumbuhan yang ditanami dengan media hidroponik bisa berkembang dan dapat tumbuh dengan waktu singkat (Singgih, Prabawati, and Abdulloh 2019)

Sistem NFT sendiri merupakan teknik budidaya hidroponik yang prinsip kerjanya mengalirkan air pupuk (kira-kira $3 \mathrm{~mm}$ ) ke talang air secara terus menerus.
Air mengalir secara gravitasi dari bagian tinggi ke rendah. Oleh karena itulah ketinggian talang air diatur dengan kemiringan 2-5\%. Untuk mengalirkan air pupuk menggunakan pompa air, lalu masuk ke bak penampungan. Dengan teknik ini tanaman mendapat pasokan air pupuk yang sama sehingga dapat tumbuh seragam. Bibit tanaman akan diletakkan dan tumbuh pada lapisan rockwoll dengan sebagaian akar tanaman dalam air yang berisi larutan nutrisi yang disirkulasikan secara terus menerus dengan menggunakan pompa, dimana daerah perakaran dalam larutan nutrisi bisa berkembang dan tumbuh pada larutan nutrisi.

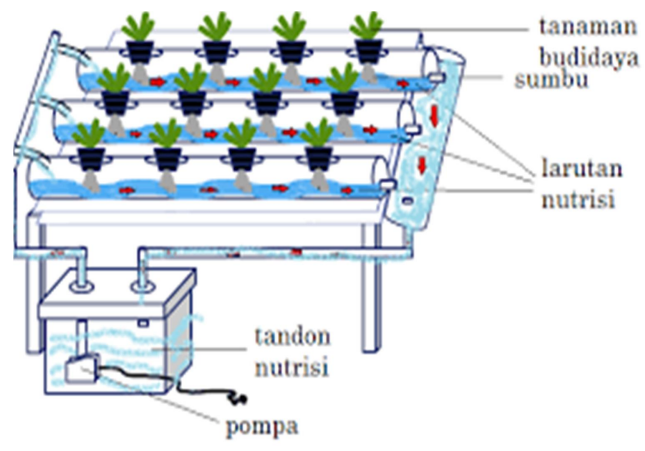

Gambar 1. Rancangan Instalasi NFT Sumber: (Kamalia dkk, 2017)

Adapun cara menanam menggunakan media hidroponik NFT ini antara lain :

1. Persiapan Alat

Pertama menyiapkan peralatan yang digunakan untuk membuat media tanam hidroponik NFT. Alat yang digunakan antara lain hand bor, satu 
set hole saw, meteran, penggaris, cutter, spidol.

2. Proses Pembuatan

Membentuk pipa PVC sesuai dengan yang di inginkan. Mengatur jumlah lubang dan jarak dengan jaraknya tak terlalu berdekatan, setelah lubang pada pipa paralon selesai dibuat maka dilanjutkan dengan proses penanaman dengan menggunakan media tanam rockwoll. Adapun tahapan proses penanaman sebagai berikut :

a. Meletakkan benih semai ke tengah netpot yang sudah diberi rockwoll yang ada di paralon.

b. Media tanam yang digunakan adalah rockwoll.

c. Rockwoll yang ditumpangkan pada netpot dipotong dengan ukuran $1,5 \mathrm{~cm}$

d. Pada rockwoll tersebut di masukan 2 biji anak semai atau sesuai kebutuhan.

e. Bila anak semai tidak menyentuh larutan nutrisi, maka potong kain flanel dan letakkan di dasar netpot dengan ujung kain menyentuh larutan. Kain flanel ini berguna sebagai sumbu pengantar larutan ke akar anak semai.

f. Memasukkan rockwoll yang sudah diberi bibit semai ke netpot, kemudian masukkan netpot pada pipa yang sudah dilubangi.

Adapun proses perawatan tanaman pada media Hidroponik NFT sebagai berikut:

a. Pada proses perawatannya yang harus sangat diperhatikan adalah pemberian nutrisi pada tanaman agar mempercepatt pertumbuhan.

b. Mengecek kondisi air di bak penampungan agar tanaman tidak kekurangan air karena dapat menghambat pada pertumbuhan tanaman.

c. Pembersihan berkala media tanaman dari lumut atau jamur yang menempel pada media tanam.

d. Pengecekan kondisi tanaman secara berkala apabila ada yang terserang hama buang dan jauhkan tanaman yang sakit dari tanaman yang sehat.

\section{Budidaya Hidroponik Sistem Wick System}

Menurut Putera (2015), jenis Hidroponik yang paling banyak digunakan saat ini adalah wick system. Wick System atau system sumbu merupakan system hidropnik statis atau pasif yang mengendalikan prinsip 
kapilaritas air melalui penggunaan kain sebagai perantara. Teknik statis ini merupakan teknik termudah yang dapat dilakukan semua orang, khususnya para pemula.

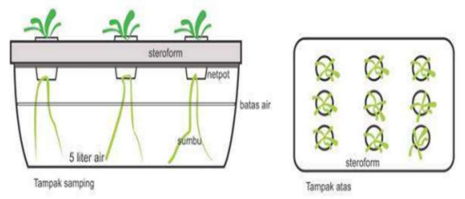

Gambar 2. Instalasi Wick System

Sumber: (Asriani dkk, 2020)

Wick hydroponics atau system sumbu merupakan metode hidroponik yang paling sedrhana karena hanya memanfaatkan prinsip kapilaritas air. Larutan nutrisi yang di alirkan dari bak penampungan menuju perakaran tanaman yang berada di atas dengan perantara sumbu.

Hidroponik sumbu (wicks) adalah salah satu metode hidroponik yang sederhana dengan menggunakan sumbu sebagai penghubung antara nutrisi dan bagian perakaran pada media tanam.

Salah satu kelemahan hidroponik sistem sumbu yaitu larutan nutrisi tidak tersirkulasi sehingga rawan ditumbuhi lumut, pertumbuhan tanaman sedikit lebih lambat. Pemanfaatan hidroponik system sumbu tersirkulasi memiliki kelebihan secara khusus yaitu kombinasi kedua sistem hidroponik ini yaitu larutan nutrisi dapat tersirkulasi serta volume larutan hara yang dibutuhkan lebih rendah.

Kelebihan lain dari sistem ini yaitu larutan nutrisi dalam keadaan tersedia, sirkulasi mencegah lumut, bersih dan mudah dikontrol, tanaman tumbuh dengan optimal, umur panen menjadi lebih singkat dan penggunaan nutrisi yang efisien. Namun kekurangan sistem tersebut yaitu biaya investasi cukup mahal. (Kamalia, Dewanti, and Soedradjad 2017b).

Menurut (Subandi et al. 2020) sistem sumbu bekerja dengan proses yang disebut aksi kapiler. Sumbu menyerap air yang dibenamkan seperti spons, dan ketika bersentuhan dengan media tanam yang berpori, ia memindahkan larutan nutrisi. Hidroponik sistem sumbu hanya berfungsi jika disertai dengan media tanam yang mampu memfasilitasi pemindahan nutrisi dan air. Sabut kelapa (serat dari kulit luar kelapa) memiliki retensi kelembaban yang sangat baik dan manfaat tambahan berupa $\mathrm{pH}$ netral. Perlite juga memiliki $\mathrm{pH}$ netral dan sangat poreus, sehingga ideal untuk sistem sumbu. Vermikulit juga sangat berpori, dan juga memiliki kapasitas pertukaran kation yang tinggi. Ini berarti dapat menyimpan nutrisi untuk 
digunakan. Adapun Keistemewaan sistem sumbu :

a. Sederhana: Sistem sumbu dapat diatur oleh siapa saja dan tidak menuntut perhatian berlebihan setelah dibuat. Sumbu akan terus memasok tanaman kita dengan air, sehingga tidak ada risiko tanaman mengering. Selain itu, tanaman seperti selada akan tumbuh subur dalam sistem sumbu.

b. Hemat ruang: Sistem sumbu tidak mengganggu dan dapat dipasang di mana saja, karena tidak memerlukan tenaga listrik. Ini adalah sistem yang cocok untuk pendidik, pemula atau siapa pun yang tertarik untuk belajar budidaya hidroponik.

Sedangkan kelemahan dari system sumbu antara lain :

a. Keterbatasan: tanaman tomat harus berjuang untuk berkembang dalam sistem sumbu karena tingginya permintaan akan nutrisi dan aliran air. Tanaman umbi seperti wortel dan lobak tidak bisa dalam sistem sumbu.

b. Rentan terhadap pembusukan: Sistem sumbu hidroponik selalu lembab dan lembab. Ini menciptakan risiko wabah dan busuk jamur dapat berkembang di media tanam organic dan pada akar tanaman.

Cara Membuat Hidroponik Wick System Menurut (Aminah et al. 2020)

1. Memotong botol minuman bekas menjadi dua dengan menggunakan cutter, pisau, atau gunting. Pastikan ukuran botol bagian bawah lebih besar daripada ukuran bagian atas.

2. Menuangkan air ke dalam bagian botol bawah lalu masukkan pupuk nutrisi A \& B sesuai takaran. Perbandingannya, masing-masing 5 ml untuk setiap liter air. Sisihkan.

3. Melubangi permukaan pada bagian leher botol dengan menggunakan paku kecil di beberapa titik. Lubangi juga bagian penutup botol sebagai jalur masuk sumbu nantinya.

4. Memasukkan sumbu, kain bekas, atau kain flanel ke dalam celah penutup botol yang akan dibuat. Pastikan sumbu cukup panjang di kedua sisi agar dapat menyerap air yang akan dituangkan dan juga mengenai bagian benih tanaman. Lalu letakkan dengan posisi terbalik ke dalam botol yang telah berisikan air.

5. Masukkan benih yang masih tertanam pada rockwool ke dalam bagian botol yang telah dibalik. 
6. Memastikan benih terkena dengan bagian sumbu yang sudah dibasahi dengan larutan nutrisi dan air. Anda juga bisa menggunakan media tanam seperti sekam bakar, batu bara merah yang telah dihancurkan, serta spon untuk menjaga bentuk tanamanan agar tiduk mudah patah.

7. Meletakkan wadah di area yang ramah sinar matahari namun tidak rawan terkena hujan agar benih tumbuh dengan baik.

8. Melakukan proses tersebut untuk membuat media tanam lainnya.

\section{Dokumentasi Hasil Kegiatan}

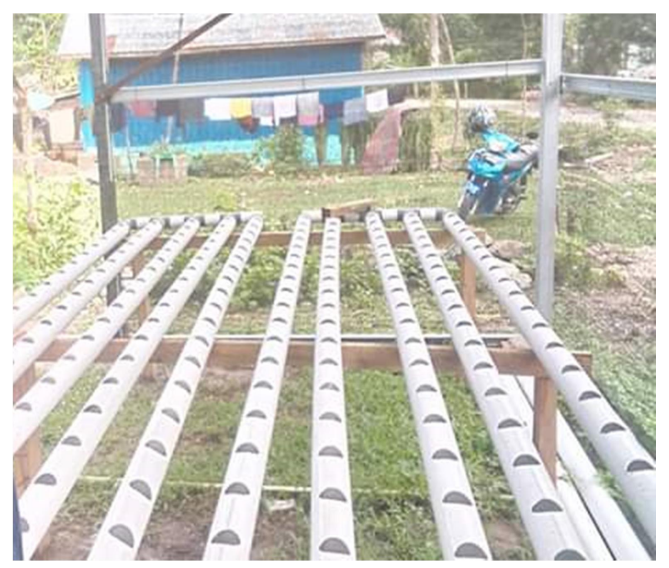

Gambar 3. Sistem NFT

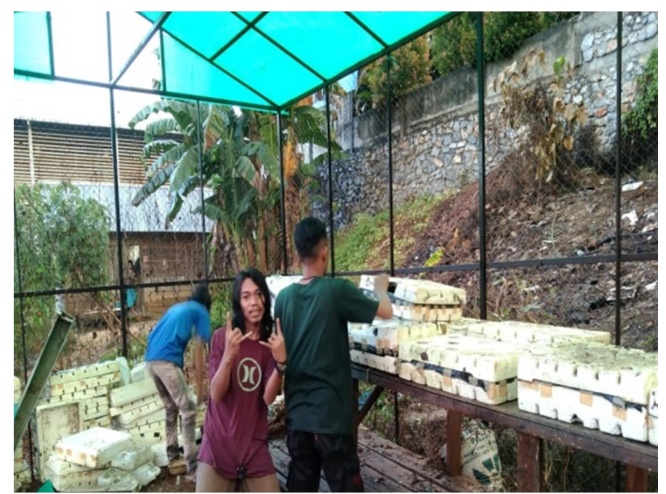

Gambar 4. Sistem Wick
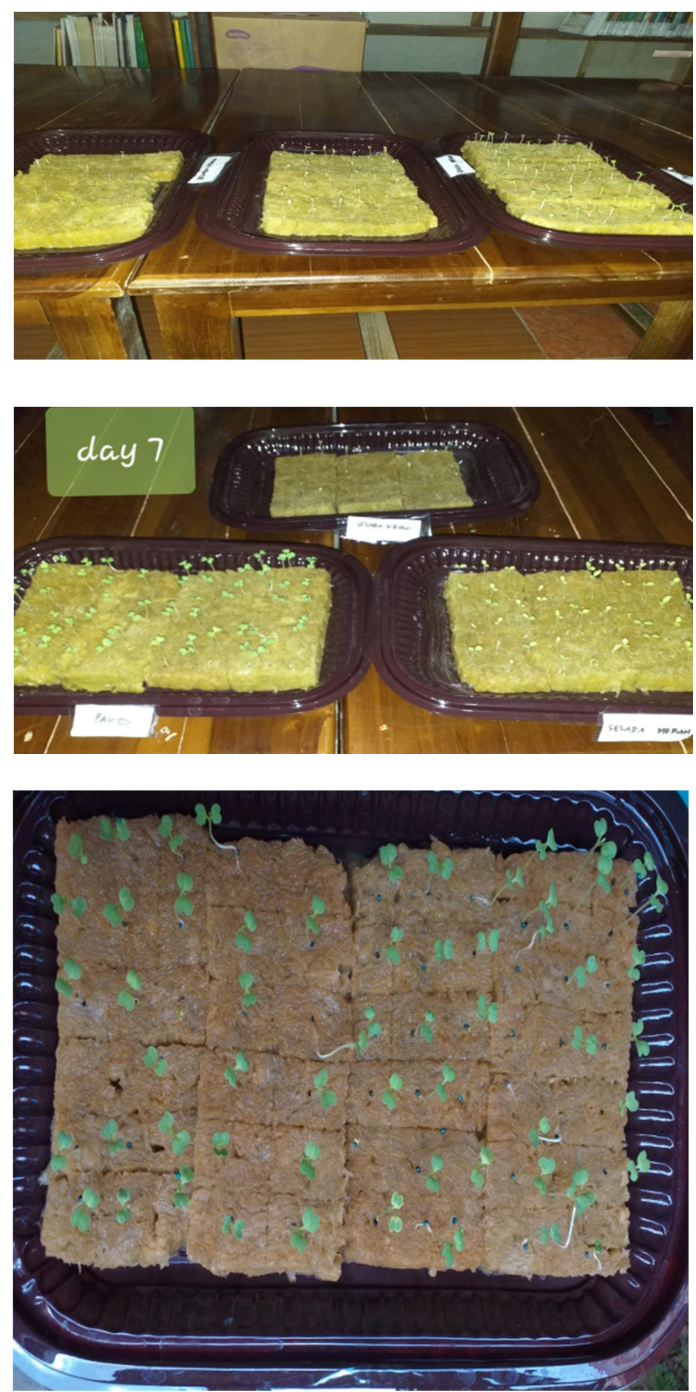

Gambar 5. Pembibitan 


\section{Jenis-Jenis Sayuran Hidroponik Sawi Hidroponik}

Metode hidroponik adalah suatu metode untuk menumbuhkan tanaman didalam larutan nutrisi tanpa menggunakan tanah sebagai media tanamnya. Hidroponik juga telah membuktikan bahwa untuk menumbuhkan tanaman tidak diperlukan tanah, kecuali unsur- unsur, mineral dan zat- zat makanan seperti dalam tanah. Dalam hidroponik, selain kita mengeliminasi tanah sebagai media tanam, kita juga bisa mengeliminasi hama tau penyakit yang bisa di timbulkan dari tanah. Larutan hidroponik mengandung nutrisi makanan untuk tumbuhan dengan menggunakan perbandingan yang tepat, ini bisa berakibat stress pada tanaman berkurang, tanaman menjadi lebih cepat matang dan kualitas panen yang didapat pun menjadi lebih baik. Ada beberapa jenis media tanam yang boleh dipakai dalam hidroponik, antara lain pasir, tembikar, arang, dan serabut kelapa. (Wirawati and Arthawati 2021).

\section{Selada Hidroponik}

Salah satu tanaman yang dapat dibudidayakan secara hidroponik yaitu selada. Selain itu selada (Lactuca sativa L.) merupakan salah satu sayuran yang memiliki kandungan kalsium cukup tinggi yaitu sebesar $56 \mathrm{mg} / 100$ gram jika dibandingkan dengan sayuran lainnya (International Osteoporosis Foundation, 2015). Selada dapat dikonsumsi sebagai salah satu pilihan terbaik untuk mencukupi kebutuhan kalsium harian. Pemanfaatan teknologi hidroponik diharapkan mampu memperbaiki produksi selada (Lingga, 2002). Adanya pemanfaatan teknologi hidroponik diharapkan mampu meningkatkan kandungan kalsium secara efisien didukung dengan adanya pemenuhan nutrisi yang sesuai bagi tanaman disertai dengan penambahan kalsium secara ekternal ke dalam nutrisi hidroponik yang digunakan. Tanaman selada akan menunjukkan respon pertumbuhan yang baik pada konsentrasi $250-320$ ppm (400 $\mu \mathrm{S} / \mathrm{cm}-500 \mu \mathrm{S} / \mathrm{cm})$ selama masa pembibitan. Rata-rata tanaman selada memiliki tingkat EC maksimal pada kisaran 2.0-3.0 mS/cm (Siregar et al., 2015).

\section{Pakcoy Hidrponik}

Tanaman pakcoy (Brassica Rapa L.) termasuk dalam jenis sayuran yang masih dalam keluarga Brassicaceae. Berat tanaman pakcoy berkisar 200-250 g, memiliki ukuran yang tidak terlalu besar, dan umur tanam dari tanaman pakcoy yaitu 40 hari mulai dari 
penyemaian sampai panen. Sehingga tanama pakcoy sangat cocok dibudidayakan dengan sistem hidroponik (Salam 2020) dalam (Nobel, 2019).

Pakcoy (Brassica rapa L.) termasuk dalam golongan tanaman sawi yang mudah di dapat dengan harga yang ekonomis. Tanaman pakcoy memiliki banyak kandungan yang dibutuhkan tubuh dan bermanfaat bagi kesehatan karena mengandung banyak vitamin, mineral, dan serat (Maulizar 2020) dalam (Sarido \& Junia, 2017) Kebutuhan pakcoy terus meningkat seiring dengan tingginya permintaan akan sayuran pakcoy.

\section{KESIMPULAN DAN SARAN}

Hidroponik merupakan teknologi tepat guna dibidang pertanian yang perlu untuk dikembangkan dalam upaya meningkatkan ketersediaan sayuran melalui pemanfaatan lahan sempit terutama pada daerah perkotaan.

Rancangan usaha budidaya hidroponik yang telah dilakukan pada kebun percontohan terdiri dari dua sistem hidriponik yakni sistem sistem Nutrient Film Technique (NFT) dan Wick system dan diharapkan hasil rancangan usaha tersebut menjadi wadah bagi mahasiswa dan masyarakat untuk meningkatkan pengetahuan tentang teknologi tepat guna hidrponik dan juga menjadi star up dalam pengembangan wirausaha.

Adapun saran dari kegiatan ini adalah perlu adanya kerjasama antara kampus, pemerintah daerah dan pengusaha dalam upaya menjamin keberlanjutan usaha budidaya hidroponik.

\section{UCAPAN TERIMAKASIH}

Terima kasih kepada Lembaga Penelitian, Publikasi dan Pengabdian Masyarakat (LP3M) Universitas Muhammadiyah Kendari, Ristekdikti, LPDP dan semua pihak pelaksana program Riset Keilmuan.

\section{DAFTAR PUSTAKA}

Aminah, Iin Siti, Rosmiah Rosmiah, Heniyati Hawalid, Lulu Yuningsih, and Helmizuryani Helmizuryani. 2020. "Penyuluhan Budidaya Tanaman Sayur Kangkung (Ipomoea Reptans) Melalui Sistem Hidroponik Di Kelurahan AlangAlang Lebar Kota Palembang." Altifani: International Journal of Community Engagement 1(1). doi: 10.32502/altifani.v1i1.3010.

Asriani, Herdhiansyah, D. 2020. Seminar Nasional Virtual.

Asriani, Asriani, Wa Embe, Fitria Nafu, and Dhian Herdhiansyah. 2020. "Persepsi Masyarakat Terhadap Agribisnis Sayuran Metode Hidroponik Starterkit Wick Di Kota Kendari." Mimbar Agribisnis: Jurnal Pemikiran Masyarakat Ilmiah Berwawasan Agribisnis 
6(1):11. doi: 10.25157/ma.v6il.2595.

Kamalia, Siti, Parawita Dewanti, and Raden Soedradjad. 2017a. "Teknologi Hidroponik Sistem Sumbu Pada Produksi Selada Lollo Rossa (Lactuca Sativa L.) Dengan Penambahan Cacl2 Sebagai Nutrisi Hidroponik." Jurnal Agroteknologi 11(1):96. doi: 10.19184/jagt.v11i1.5451.

Kamalia, Siti, Parawita Dewanti, and Raden Soedradjad. 2017b. "Teknologi Hidroponik Sistem Sumbu Pada Produksi Selada Lollo Rossa (Lactuca Sativa L.) Dengan Penambahan Cacl2 Sebagai Nutrisi Hidroponik." Jurnal Agroteknologi 11(1):96. doi: 10.19184/jagt.v11i1.5451.

Masduki, Anang. 2018. "Hidroponik Sebagai Sarana Pemanfaatan Lahan Sempit Di Dusun Randubelang, Bangunharjo, Sewon, Bantul.' Jurnal Pemberdayaan: Publikasi Hasil Pengabdian Kepada Masyarakat 1(2):185. doi: 10.12928/jp.v1i2.317.

Maulizar, Siti. 2020. "Budidaya Pakcoy (Brassica Rapa L.) Dengan Menggunakan Teknik Hidroponik Sistem Nutrient Films Technique
(NFT) Budidaya Pakcoy (Brassica Rapa L.) Dengan Menggunakan Teknik Hidroponik Sistem Nutrient Films Technique (NFT)." (2016).

Roidah, Ida Syamsu. 2014. "Pemanfaatan Lahan Dengan Menggunakan Sistem Hidroponik." 1(2):43-50.

Salam, Andi Yulia Rezti. 2020. "Analisis Kelayakan Ekonomi Hidroponik Selada Dan Pakcoy (Studi Kasus: Hidroponik Pakkatto)."

Singgih, Mohammad, Kusuma Prabawati, and Dhiyaul Abdulloh. 2019. "Bercocok Tamam Mudah Dengan Sistem Hidroponik NFT." Jurnal Abdikarya: Jurnal Karya Pengabdian Dosen Dan Mahasiswa 03(1):21-24.

Subandi, M., Suryaman Birnadi, Salamet Ginandjar, and Budy Frasetya. 2020. "Identifikasi Arah Pengembangan Riset Dan Tinjauan Sistem Teknik Budidaya Hidroponik Di Indonesia." 14.

Wirawati, Sri Mukti, and Sri Ndaru Arthawati. 2021. "Pengenalan Metode Hidroponik Budidaya Tanaman Sawi Untuk Meningkatan Pendapatan Masyarakat Di Desa Pelawad Kecamatan Ciruas." 3(1):1-9. 